\title{
sciendo
}

\section{Framework for assessing innovation capacity and business efficiency in Romanian SMEs}

\author{
Ioana Alexandra ONEA \\ Bucharest University of Economic Studies, Bucharest, Romania \\ ioana_alexandra_o@yahoo.com
}

\begin{abstract}
The purpose of this paper is to provide a new framework for assessing the innovation capacity and efficiency in Romanian small enterprises and start-ups. In this sense, a systematic literature review has been employed in order to obtain a clear understanding of the existing knowledge and to critically evaluate the existing solutions. In addition, considering the European Union objectives regarding innovation and sustainable development, this paper investigates the present situation of Romania by interpreting the official European Commission reports and current research papers. Considering the importance of regional innovation advancement and that of creating economic growth through competitiveness, this paper scrutinizes several concepts from the scientific literature, including regional innovation governance, entrepreneurship and innovation efficiency with the final purpose of developing a framework applicable for Romania. Taking into consideration the relatively low scores of Romanian regions regarding innovativeness and technological advancement, this paper attempts to provide a clearer understanding of the applicable factors that can be used for measuring innovation performance. The proposed framework focuses on the importance of entrepreneurship and the development of new business models in order to efficiently assess the innovative endeavors of enterprises. All things considered, this paper provides both theoretical and managerial contributions and possibility for further investigations addressed at specific Romanian regions and business sectors.
\end{abstract}

Keywords: innovation indicators, entrepreneurship, business efficiency, small and medium enterprises, startups.

\section{Introduction}

The increasing importance of innovative national systems, which imply the cooperation of all parties, namely business owners, government, industries and workforce, is being addressed by several scholars. Guan \& Chen (2012) reveal the need for a new orientation in innovation policies and emphasize the interdependency between "agents, organizations and institutions" as a priority. The authors further acknowledge the importance of assessing innovation efficiency in order to obtain a thorough understanding of the existing weaknesses and consequently apply best practices for resolving the issues. In addition, the authors propose as solutions the implementation of national innovation systems, concepts that are developed through the cooperation between industries and governments and applied for specific "geographic units". Wang et al. (2016) further support the idea of collaboration and cooperation between several parties involved in the innovation process such as "enterprises, universities and research institutions". Moreover, the authors highlight the need for adopting regional innovation systems, characterized by knowledge sharing and cooperation between "public and private agents". In this sense, Argatu \& Păunescu (2019) reveal that achieving such objectives, related to the overall competitiveness of a country, implies multiple dimensions, such as: innovative capacity, sustainability, entrepreneurial and economic conditions. Furthermore, in order to create regional innovation systems, Wang et al. (2016) reveal the need for specific regulations and policies, "resource circulation and allocation of innovation resources". 
Considering the above implications, this paper investigates the existing concepts in the scientific literature regarding innovation efficiency and regional cooperation, with the aim to propose a framework for assessing innovation performance in Romanian start-ups and small enterprises. In this sense, this paper is structured as follows: the literature review section addresses the current state of the art in the academic literature regarding knowledge economy, regional innovation governance and innovation efficiency; the methodology section describes the methodological approach used, namely systematic literature review and the results and discussion session portrays the proposed framework and a critical analysis of the selected factors.

\section{Literature review}

\section{Knowledge economy and innovation competitiveness}

Globalization brought important changes and defined new concepts throughout the world, as per the views of Kontolaimou et al. (2016). One of such concepts is represented by the "knowledge economy", which can be defined in the understanding of the authors, as a driver of economic growth and competitive advantage for countries and global economies. Burja \& Burja (2013) reveal that knowledge economy is a concept that defines country competitiveness, with firm investments and $R \& D$ indicators as drivers for innovative endeavors. Kontolaimou et al. (2016) further suggest that the sharing of knowledge, which ultimately results into the development of new products, is interlinked with concepts such as innovation and entrepreneurship. In this sense, Dobrzanski (2018) highlights the implications of innovation for economic growth by addressing the research of many scholars, such as Schumpeter, Gartner and Drucker, Solow and Hiroka, who underlie the connection between innovation, technological change and entrepreneurship, all being tools that trigger competitiveness. Dobrzanski (2018) further highlights the importance of innovation by revealing the objectives of the European Union, namely those of improving competitiveness through innovation. Regarding these objectives, the author mentions the establishment of the European Institute of Innovation and Technology, which functions as a connector between "higher education, research and business-innovation". Szabo \& Herman (2012) further insist on the connection between innovation and entrepreneurship, the latter being perceived as a key factor in the overall economic development. The authors acknowledge the Schumpeterian idea according to which entrepreneurship is a driver of productivity and growth in either "advanced industrialized countries", as well as in "emerging developing economies". Kontolaimou et al. (2016) analyze the impact of "early- stage entrepreneurship" in overall country competitiveness and conclude that entrepreneurial efforts can be the catalyst for technological heterogeneity and national innovation efficiency.

Following the importance of country competitiveness, Zaman \& Blănaru (2008) describe three factors as relevant for highlighting a country's competitive advantage, namely the impact of production factors, the impact of investments and finally, the role of innovation. The first factor, namely production factors, refers to the creation of sustainable innovation and development. Ceptureanu et al. (2020) explain that small and medium enterprises are more prone to create sustainable development and drive eco-innovation, considering their internal setting and their strong focus on strategy. The authors acknowledge that combining the long-term focus on strategy and existing resources can lead to implement "sustainable innovation practices". The second factor highlighted by Zaman \& Blănaru (2008) refers to the importance of firm investments. The authors acknowledge that firm investments lead to the development of "domestic competition" and the creation of an "internal market", thus allowing the creation of economic value. Finally, the third factor, namely the role of innovation or the innovation capability refers to the ability of improving 
existing technologies or creating new ones (Wonglimpiyarat, 2010). Zaman \& Blănaru (2008) introduce the concept of "innovation competitiveness", which represents the overall inputs and outputs of research, development and innovation, as a means of creating competitive advantage. In an attempt to effectively measure how competitive countries are at a global level, the World Economic Forum issued the Global Competitiveness Report, a document with international exposure and relevance that provides an analysis over each nation's level of competitiveness and its corresponding rank (Bleotu, 2012). Furthermore, Diaconu (2015) reveals the indicators introduced by various international bodies, having as objective the creation of a comparison between nations around the world and identifying the existing gaps. In this sense, the author describes the Global Competitiveness Index as a metric for measuring countries' competitiveness. The index comprises various factors that describe competitiveness in a country, grouped into 12 pillars. Innovation capacity is a constituent of the Global Competitiveness Index, therefore, the interdependency between innovation and competitiveness is analyzed by Diaconu (2015). In this regard, according to the author's research, Romania is placed 59th place from 144 countries regarding the competitiveness index and 66th place regarding the current level of innovation. The connection between the relatively low score of Romania in both metrics, namely competitiveness and innovation, is explained by the lack of technology heterogeneity and weak level of innovation in the R\&D process. As suggested by Burja \& Burja (2013), a good performance of the R\&D process is influenced by the firm investments. Considering the specific case of Romania, the authors explain the low score on technological development through the poor public investments and the reduced foreign direct investments. Using the data envelopment analysis, Dobrzanski (2018) proposes a solution for increasing the efficiency of the R \& D sector. In this sense, the author proposes the separation of efficient units from inefficient ones by dividing the outputs and the inputs. Considering this calculation, Romania is "close to the efficiency frontier", therefore solutions can be found in implementing innovation policies and organizational endeavors for improving firm investments (Dobrzanski, 2018).

By describing Porter's competitive diamond model, which presents several determinants of national innovation, Wonglimpiyarat (2010) states that in order for a country to be considered competitive, its innovation capability should be assessed on five levels, namely organization, process, service, product and marketing. In this sense, the author proposes several recommendations, namely: government funding for "innovative start-ups", especially small businesses, meaning venture capital financing schemes, loan programmes and supportive regulations; national policies for driving innovation development, and finally, a redirection of focus towards technological advancement, through the development of technology hubs and innovation centers. Falciola et al. (2020) acknowledge the importance of competitiveness and its implications in creating competitive advantages for enterprises. Păunescu et al. (2018) further support the idea that enterprises must identify their vulnerabilities, priorities and resources in order to plan for improving the existing products and services, and thus, drive competitive advantage. For the specific case of Romania, the authors reveal the importance for organizations to create business continuity plans, which should encompass the resources, expertise and knowledge as well as the current use of technology and information at enterprise level. In a research performed by Păunescu \& Argatu (2020), the authors emphasize the importance of applying business continuity plans for small and medium enterprises. Both in Romania, as well as at European level, SMEs do not implement effective strategies in order to cope with unforeseen risks. By applying and developing strategies in order to address operational risks and damages, SMEs can further compete with other 
large organizations, despite not benefiting from the same economic and human resources, as acknowledged by Păunescu \& Argatu (2020).

\section{Regional innovation governance and entrepreneurship}

Dodescu \& Chirilă (2012) state the importance of innovation at national and global level by addressing the concept of "regional innovation governance". The authors reveal that this concept involves the collaboration of various institutions and several actions in order to develop regional structures or local clusters meant to function as "networks of innovation". The authors describe that throughout Europe this concept has gained increased importance over the past 20 years and much attention has been given towards how nations adopted and applied the regional governance approach. In this sense, the Regional Innovation Scoreboard is a yearly report provided by the European Commission in an attempt to respond to the need of European countries to embrace the regionalization process. This report analyzes the adopted regionalization of each country according to several pre-established innovation indicators. In this sense, the manner in which countries follow this approach differs. The literature reveals several types of regionalization, such as "administrative, by cooperation between existing local collectivities, regional decentralization, political regionalization" and finally, "regionalization by federal authorities" (Dodescu \& Chirilă, 2012). For the specific case of Romania, the authors reveal that the regionalization approach adopted is "by cooperation between existing local collectivities". In this sense, Caramihai et al. (2017) propose two models that could act as facilitators for the adopted regionalization approach. In this regard, the authors describe the business incubators and the establishment of clusters as means to achieve a better collaboration between organizations. Business incubators serve as nonprofit organizations that support entrepreneurial efforts and facilitate the cooperation between different small business enterprises and start-ups. Following this line of thought, business incubators foster "innovation and technology transfer" for small enterprises with training, business strategies and coaching (Caramihai et al., 2017). According to the authors, another facilitator for innovation and technological advancement is a cluster, which is formed by several small companies, start-ups and other organizations, with the purpose to share knowledge, information and foster collaboration.

Kravtsova \& Radosevic (2012) describe the existing context in Eastern Europe in the late 1990s. The authors report that the transition from a "conventional economic perspective" to a sustainable development based on technical change was challenging for countries from Eastern Europe. Their paper explored the factors that influenced technological advancement from an innovation perspective. The low levels of productivity revealed in Eastern European countries can be explained by understanding the difference between productivity and technological capability. In this sense, Kravtsova \& Radosevic (2012) explain that production capabilities embody the product specifications, organizational strategy and existing skills, while technological capability drive technical change through linkages, knowledge and experience. In this sense, the concept of knowledge economy, which fosters economic growth, is a pillar for production capability, while technical change implies a shift of focus on R\&D and innovation. Following this line of thinking, the Eastern European countries characterized by developing economies failed to advance technological development, due to a focus of efforts into production capability. These findings apply for Romania as well. In this sense, Talmaciu (2012) highlights that the transition economy took place in Romania after 1989 and was characterized by the "radical restructuring" of the economy from industrial districts towards a capitalist economy, characterized by the initiation of entrepreneurial endeavors and the arrival of many small and medium enterprises. After becoming 
part of the European Union, Romania had to align and adapt to the goals proposed by the European Commission, as part of the European integration (Dodescu \& Chirilă, 2012). In this sense, the authors acknowledge the need for a pluralism of actors involved in the process of developing new strategies and highlight the need for regional cooperation and the impact of Romania's regions regarding the status of the innovative efforts. Furthermore, the authors reveal the innovation, entrepreneurship and knowledge sharing, namely educational endeavors are the main factors that create discrepancies between Romanian regions. In this sense, the National Authority for Scientific Research exposed the current status of innovative activities in the eight regions established for Romania, namely Bucharest-Ilfov, South-East, North-West, North-East, Centre, South-Muntenia, West and South-West Oltenia. Considering that one of the initiatives of the European Commission is to link economic growth with innovation, the Regional Innovation Scoreboard defines regions according to several innovation indicators (Popescu, 2014). In this sense, Bucharest-Ilfov has scored the highest, being categorized as a moderate innovator, while all other regions scored low, being considered modest innovators. Popescu (2014) explains this as a consequence of the majority of SMEs adopting internal R\&D processes, while only a small percentage, $7.48 \%$, consider collaboration with other enterprises in their R\&D activity.

In addition, an analysis performed by Roman (2010), which examined the R\&D efficiency in Romanian regions, shows that Bucharest-Ilfov is the most technical efficient, while all the other regions have a low efficiency score. However, at overall country level, Romania is still considered a modest innovator, due to the low preponderance of technology sectors and a lack of intellectual output turned into competitiveness, as highlighted by Iancu (2014). In the own acceptance of Talmaciu (2012), the development of a regional strategy could represent a solution and drive innovation in Romanian regions and SMEs. According to the author and based on the data provided by the European Cluster Excellence, there are "38 innovative clusters" in Romania, the most numerous being located in the Central and Bucharest-Ilfov region, followed by the North-West and North-East regions, with a total of 10 clusters which include industries such as green and renewable technologies, ICT, tourism and agro food. Therefore, we can conclude that cooperation between regions is a possible solution with a successful impact on small enterprises due to the creation of “connections between managers and capital holders" (Talmaciu, 2012). Păunescu \& Molnar (2020) focus on the relevance of the regulatory environment in which small and medium enterprises can be developed. In this sense, the authors agree that in Romania, the governing framework is less favorable than in other countries from the European Union. Although visible progress has been made, mostly in terms of financial support for small and medium enterprises, for the specific case of Romania, there is room for better improvement initiatives regarding the regulations and administrative interaction between several state institutions and small and medium enterprises.

\section{Innovation efficiency}

The idea that innovation is a catalyst for goods and services which results in economic growth is part of the European Commission Strategy, namely Europe 2020 (Matei \& Aldea, 2012). In this sense, the authors reveal that the 27 member states of the European Union must adapt to several objectives regarding innovation performance and change. Following this line of thought, the author's analysis acknowledges the importance for European countries to develop National Innovation Systems. In a research performed by Dobrzanski (2018) there is mentioned a new innovation indicator specifically directed towards the policy makers in order to support small businesses and start-ups. The indicator of innovation output focuses on the knowledge generated by the adoption of new technologies, the employment generated by the implementation of such 
technologies, the competitiveness between innovative goods and services and finally, on the number of innovative firms that operate in various business sectors (Dobrzanski, 2018). Considering the case of Romania, amongst the 27 member states of the European Union, Romania is part of the modest innovators cluster with a "catching-up" economy (Sandu et al., 2015).

In the opinion of the authors, the European Innovation Scoreboard is a report that attempts to provide a measure for innovation performance by introducing three categories of innovation indicators. In this sense, the main groups of innovation indicators are represented by Enablers, Firms activities and Outputs; enablers refer to key drivers of innovation, namely human resources, quality and functionality of R\&D systems and "availability of finance for innovation projects"; firm activities incorporate the "innovation generators" such as R\&D activities, "entrepreneurial and collaboration efforts" and intellectual property rights; outputs encompass the results of enterprises innovative endeavors, meaning the actual innovation activities implemented and the economical results of such activities (Sandu et al., 2015). Considering the concerns regarding the efficiency of innovation, Tilebein (2006) proposes a new concept, namely complex adaptive systems (CAS) that measure the efficiency by taking into consideration two factors: spontaneity and evolution over time. According to the authors, this system is flexible and therefore, suitable for changing environments. Furthermore, in order to measure innovation efficiency, Dobrzanski (2018) proposes a nonparametric methodology, namely data envelopment analysis. According to the author, this method has applications in measuring both technical efficiency as well as the efficiency of the decision making process implied in the transformation. Hsu (2011) further supports the idea of measuring the innovation performance through the analysis of small and medium enterprises (SMEs). In the research performed, the author identifies several types of SMEs that could be used for determining the innovation performance in a region or in a country, namely SMEs innovation in house, SMEs based on collaboration with other enterprises and SMEs that innovate using non-technological change.

Zygiaris (2009) acknowledges the importance of enterprise investment in innovation and assigns the low score on innovation performance to the lack of employing new technologies in order to deliver innovative results. The author identifies the lack of use of new technologies as one of the reasons Romania is considered a modest innovator. Ionescu (2015) supports this idea by addressing the existing challenges of the Romanian RDI system. In this sense, the author highlights that Romania is characterized by "low and medium technology based sectors", which is a confirmation of an "underdeveloped culture of innovation". Badulescu \& Cadar (2016) further insist on the importance of entrepreneurship and its connection to innovation, referring to enterprises adopting new business models. The authors acknowledge the definition provided by the Global Entrepreneurship Monitor, which states that an innovative entrepreneur is the one who introduces new products or services on the market. However, the authors highlight the scenario in which a country is characterized by many entrepreneurial activities but few innovative ones. When addressing the particular case of Romania, Badulescu \& Cadar (2016) mention that Romania has the highest rate of "intentional entrepreneurs" and "young business entrepreneurs" (with high values between 25-34 years old and 35-44 years old) when compared to other countries from Central and Eastern Europe. In addition, the authors conclude that even though the rates of entrepreneurial intention are high for Romania, the discrepancies between the three main pillars considered, namely entrepreneurship, innovation, competitiveness manage to place Romania as a modest innovator. 


\section{Methodology}

The selected methodology for this paper is a systematic literature review, which is considered part of the qualitative research methodologies. A qualitative research methodology has various characteristics that make this method more appropriate considering the researched theme in this paper, namely developing a framework for assessing business efficiency and innovation capacity. In this sense, according to Patton (1990), the qualitative research approach allows the topic to be discussed in detail, which provides a good validity of the results considering the accuracy of the analysis. According to Saunders et al. (2012) and considering that this paper critically assesses the factors that constitute the proposed framework, the analysis is descriptive and explanatory, thus providing several contributions to the existing knowledge. Macdonald-Jankowski \& Dozier (2003) support this idea by addressing the processes implied in developing an effective analysis of the paper topic. In this sense, for the purposes of this paper, an initial acknowledgement of the topic has been performed in order to have an overview of the key drivers implied in defining the country's innovation capacity and the implications for business efficiency. Moreover, several frameworks from the literature are explored and analyzed in order to create a satisfactory framework applicable to the reality in Romania and Romanian small enterprises or start-ups.

Furthermore, of critical relevance for achieving the objectives of this study are the information sources used in the process. In this sense, several scientific sources from the literature, namely journals, articles and books, available on various academic databases have been used. Following this idea, the databases used (Emerald, Science Direct, ProQuest) are included on the renowned platform Web of Science. The journals used for the purposes of this paper are: "Social and Behavioral Sciences", " Annales Universitatis Apulensis Series Oeconomica", "Procedia Engineering", "Sustainability", "The USV Annals of Economics and Public Administration", "Economics and Finance", "Research evaluation", " African Journal of Business Management", "Economic Modeling", "Economic Systems", " International Journal of Entrepreneurial Behaviour \& Research", "Futures", " The Journal of the Romanian Regional Science Association", "Research Policy"," Technology Analysis \& Strategic Management". The articles have been chosen by using two factors, namely the first referring to the general context of the studied topic, and the second one implied specific keywords related to the in-depth performed analysis. Such keywords used are: "innovation performance", "innovation efficiency", "business entrepreneurship", "small and medium enterprises".

\section{Results and discussions}

Considering the literature review and the models analyzed, this paper aims to propose a framework for assessing innovation capacity and the resulting business efficiency for Romanian small enterprises and start-ups. Following this line of thought and the current results for Romania at European level, namely Romania being considered a modest innovator, Edquist et al. (2018) question the relevance of the innovation indicators presented in the European Innovation Scoreboard for measuring innovation efficiency. In this sense, the authors highlight the importance of considering both inputs and outputs when measuring innovation in a particular country or region. By adding the economic impact, the authors further insist on acknowledging the resources used in the process and the budget constraints. Edquist et al. (2018) assess the applicability of the Summary Innovation Index as an overall indicator used for measuring innovation performance and insist on the importance of productivity, namely that of evaluating the innovation inputs and outputs specific 
for the region or country considered. The figure below portrays a classification for the innovation indicators used for determining the Summary Innovation Index.

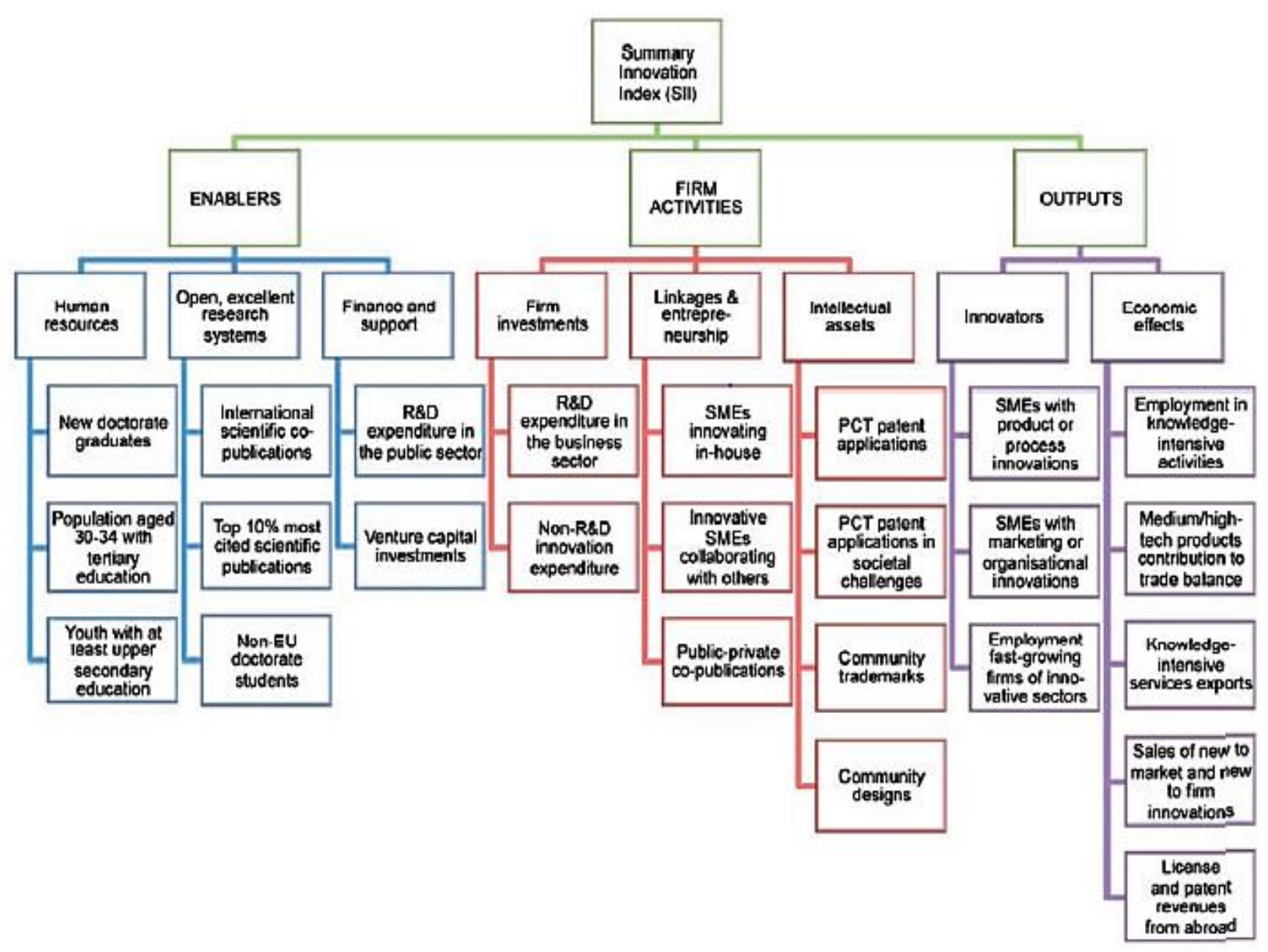

Figure 1. Summary Innovation Index

Source: "On the meaning of innovation performance: Is the synthetic indicator of the Innovation Union Scoreboard flawed?", Edquist et al. (2018).

One of the objectives of this study, apart from developing a framework for assessing innovation performance and capacity is to consider specific factors that influence Romanian enterprises and include applicability for significant Romanian regions from an innovation perspective. In this sense, starting from the Summary Innovation Index proposed in the European Commission's Report, namely European Innovation Scoreboard, which addresses as crucial factors for measuring innovation efficiency and economic performance the following: inputs or innovation drivers, positive and negative outcomes that reflect overall innovation performance and business and ultimately financial achievements, we propose the following framework to be used for measuring innovation performance in Romania. 


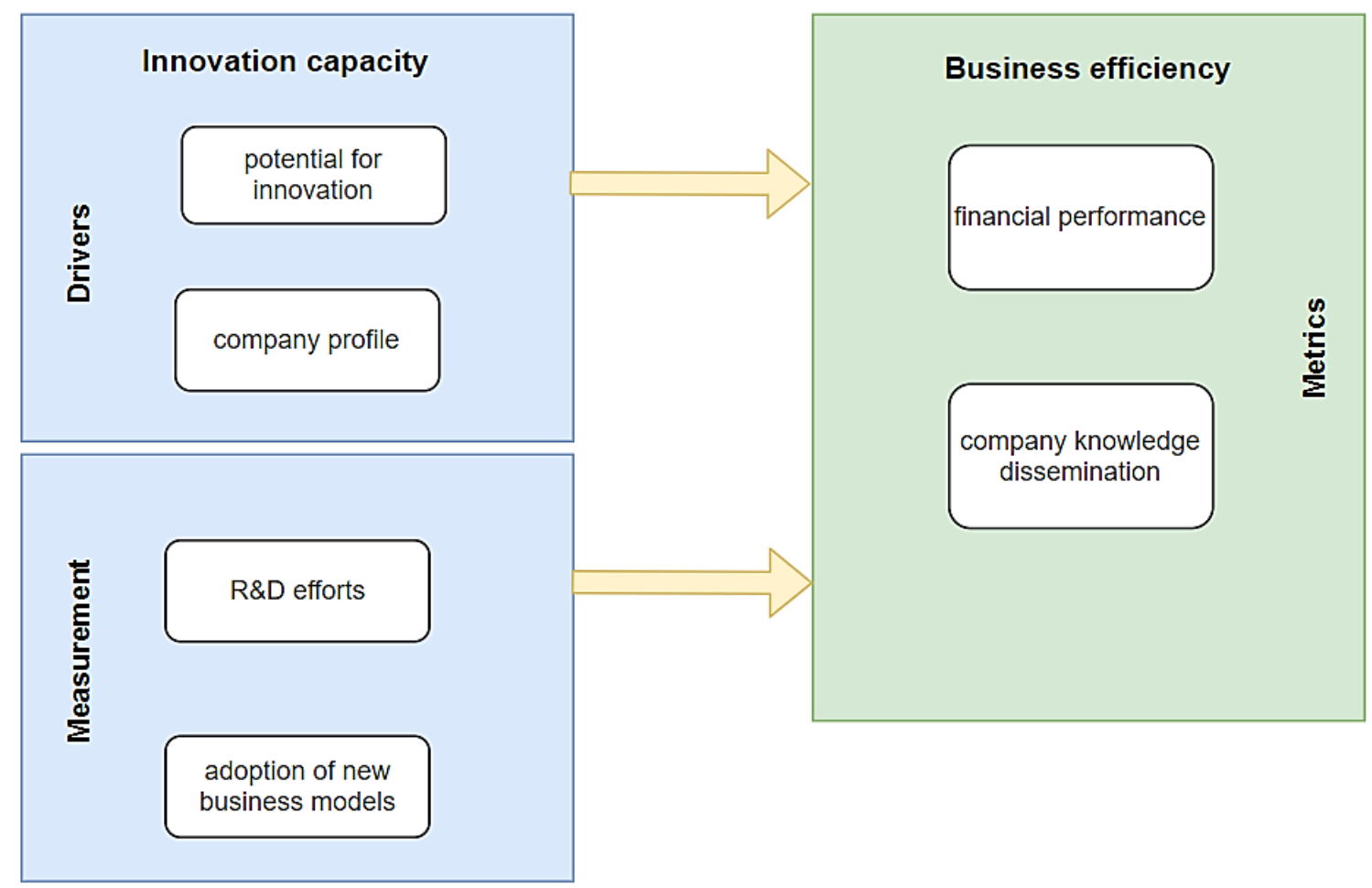

PICBE | 1091

Figure 2. Framework for assessing innovation capacity and business efficiency

Source: Author's own research.

The above framework addresses the innovation capacity, defined by Szeto (2000) as the incremental improvement of existing products or services or the development of new ones during a specific timeline. The author insists on the collaboration between the internal environment of the enterprise and the external one, thus leading to a "networked environment". In the proposed framework, innovation capacity is characterized by various drivers and measurements, ideas well supported in the literature.

In this sense, regarding the innovation capacity drivers, the potential for innovation is defined, in the own acceptance of Li (2009) by the interaction between "individuals, groups and organizations". In his paper, the author mentions that this synergy represents the foundation of any innovation system. Following this line of thinking, new knowledge stimulates individuals' creativity for generating new ideas, which results in the development of new products or services. In addition, the collaboration between firms, universities and research institutes is an incentive for governments to allocate financial resources and adopt regulations in order to encourage the innovation process. The company profile is another driver of innovation capacity because in the own acceptance of Fernandes et al. (2013) it encompasses the firm age, size and sector of activity. Regarding the firm size, the authors highlight the idea that small and medium enterprises or start-ups are more prone to innovate and adopt new ideas, when compared to larger organizations. This idea is further supported by Laforet (2010), who reveals that young entrepreneurs are more prone to develop the human resources and stimulate knowledge sharing. As a consequence, this approach can result in increased operational efficiency and reduced costs. When addressing the sector of activity, Forsman (2011) suggests that different business sectors, especially when 
referring to small enterprises, are not prone to develop extensive R\&D activities, but rather foster innovation through daily practices and adaptation of existing technologies.

Regarding the innovation capacity measurements, $R \& D$ efforts and company profile represent the most important outputs. According to Li (2009), efficiency of innovation systems is difficult to measure; therefore, other variables can be used for quantification purposes. In this regard, the investments in research and development, which translate into innovation in products and services are a measurement of a good innovation capacity of the firm (Fernandes et al., 2013). Moreover, the authors highlight that a higher impact in technological advancement will lead to better firm performance and growth. The adoption of new business models and the application of strategic management in defining new ways of operation is another measurement of the innovation capacity. In the opinion of Boly et al. (2014), the appropriate use of existing resources together with the reconfiguration of internal processes and functions can lead to innovative enterprises that create competitive advantage in a changing environment. The authors further emphasize the benefits of exploiting the existing knowledge and creating a better understanding of the routines and activities that the firms can undertake in order to deliver better performance. Ferreira et al. (2015) reveal that the organizational culture is another aspect of the business model that measures the innovation capacity. The constant drive for process improvement and the formulation of optimal solutions is a sign of a proper decision making process, focused on adopting new methodologies and generating competitive advantage. Furthermore, the authors highlight that an organizational culture open to networking can foster rapid changes in the enterprise and create access to new markets.

In the proposed framework, business efficiency is determined strictly through the connection with innovation capacity. In this sense, financial performance is, in the own acceptance of Adams et al. (2006) a natural result of the "conceptualization of the innovation process". The authors reveal that financial performance is strictly related to "market dynamics" and is a direct consequence of R\&D efforts. In this sense, Adams et al. (2006) emphasize the relevance of market planning and monitoring as part of driving financial performance. An additional metric for business efficiency is company knowledge dissemination. Although somehow considered an intangible asset, when compared to financial profits, knowledge dissemination is one of the factors that "accounts for most market value", even if not "recorded in financial statements" (Mariz-Pérez et al., 2012). According to the same authors, when considering the Kaplan and Norton's Integral Credit Scorecard Model, the intangible assets must be "aligned with the business strategy", leading to value creation and creating strategic success. Moreover, according to Adams et al. (2006), knowledge dissemination refers to the explicit and implicit knowledge of the company and stimulates the flow of information and networking. According to the author, a concept that measures the existing knowledge within a firm is the "absorptive capacity". The absorptive capacity results from the company's business model, namely from the ability to apply knowledge consumption for commercial purposes.

All in all, the proposed framework aims to provide a structure of the factors that influence the innovation capacity of enterprises and its measurement and the consequent metrics for business efficiency, an objective towards which enterprises are heading nowadays. Regarding the contributions of this paper, the main personal contribution of this paper if the developed framework for assessing business performance and innovation capacity, in order to be applied for gaining a better understanding of the factors that impact Romanian small and medium enterprises or start-ups. The proposed framework is holistic, explanatory and relevant for the specific situation of Romania. A second contribution implies the expansion of the existing knowledge in the 
scientific literature and provides opportunities for new research regarding this topic. Following this line of thought, besides the theoretical contributions, the managerial contributions are of interest, because the paper provides an overview for practitioners to understand and apply theoretical knowledge into business reality.

\section{Conclusion}

This paper explored and critically analyzed the demanding factors that characterize the innovation performance and capacity nowadays. In this sense, by using a systematic literature review, the paper provides an explanatory investigation on the economic realities and the factors that measure the innovative endeavors of companies. Starting from the European Innovation Scoreboard, this paper attempts to develop a framework used for measuring innovation efficiency and capacity for the specific case of Romanian small enterprises and startups. Following the current research, this paper provides solutions for Romania, in order to address the present status of Romania in the list of innovative countries. In this sense, being considered a modest innovator, with a developing economy, Romania should pursue effective actions towards changing the status quo in order to achieve the European Union's objectives.

This paper does not attempt to describe all applicable factors or solutions to the present situation of Romania; however, it manages to offer several clarifications in order to support new ideas for small firms and start-ups. These include the application of the knowledge-sharing concept, the possibility of creating innovation clusters and of applying new business models suitable for Romanian regions. In addition, much research is still needed. In this sense, the present paper can be further improved with a quantitative research methodology, by using surveys or questionnaires, in order to assess the current status of specific regions from Romania. In this sense, such a methodology approach would validate the proposed framework.

\section{References}

Adams, R. et al. (2006). Innovation management measurement: A review, International Journal of Management Reviews, 8(1), 21-47.

Argatu, R. \& Păunescu, C. (2019). Romania and its poverty-alleviating competitiveness: a Central and Eastern European outlook, Proceedings of the International Conference on Business Excellence, 13(1), 435-447.

Badulescu, D. \& Cadar, O. (2016). Romania: Many Entrepreneurs but Few Innovators, Retrieved from https://mpra.ub.uni-muenchen.de/78924/.

Bleotu, V. (2012). Comparative analysis of Romanian competitiveness evolution, Procedia - Social and Behavioral Sciences, 46, 5382-5386.

Boly, V. et al. (2014). Evaluating innovative processes in french firms: Methodological proposition for firm innovation capacity evaluation, Research Policy, 43, 608-622.

Burja, V. \& Burja, C. (2013). Knowledge economy and entrepreneurship environment in Romania, Annales Universitatis Apulensis Series Oeconomica, 15(2), 633-641.

Caramihai, M. et al. (2017). Proposals for improving innovation and technology transfer policies in Romania, Procedia Engineering, 181, 984-990.

Ceptureanu, S. I. et al. (2020). Eco-innovation Capability and Sustainability Driven Innovation Practices in Romanian SMEs, Sustainability, 12, 1-18.

Diaconu, M. (2015). Facing the economic competitiveness challenge in Romania: The innovation issues, The USV Annals of Economics and Public Administration, 15(2), 76-84. 
Dobrzanski, P. (2018). Innovation expenditures efficiency in Central and Eastern European Countries. Zb. rad. Ekon. fak. Rij., 36(2), 827-859.

Dodescu, A. \& Chirilă, L. F. (2012). Regional innovation governance in the context of European integration and multi-level governance challenges. A Case Study of North-West Region of Romania, Procedia Economics and Finance, 3, 1177-1184.

Edquist, C. et al. (2018). On the meaning of innovation performance: Is the synthetic indicator of the Innovation Union Scoreboard flawed?, Research Evaluation, 1-16.

Falciola, J. et al. (2020). Defining firm competitiveness: A multidimensional framework, World Development, 129, 104857.

Fernandes, C.I. et al. (2013). Drivers to firm innovation and their effects on performance: an international comparison, Int Entrep Manag J, 9, 557-580.

Ferreira, J. M. et al. (2015). Drivers of innovation strategies: Testing the Tidd and Bessant (2009) model, Journal of Business Research, 68, 1395-1403.

Forsman, H. (2011). Innovation capacity and innovation development in small enterprises. A comparison between the manufacturing and service sectors, Research Policy, 40, 739-750.

Guan, J. \& Chen, K. (2012). Modeling the relative efficiency of national innovation systems, Research Policy, 41, 102-115.

Hsu, Y. (2011). Cross national comparison of innovation efficiency and policy application, African Journal of Business Management, 5(4), 1378-1387.

Iancu, V. (2014). Romania in the context of European innovation and marketing of intellectual output, Procedia Economics and Finance, 8, 380-387.

Ionescu, C. (2015). Challenges on the integration of Romanian system research, development and innovation in Innovation Union, Procedia Economics and Finance, 32, 986-991.

Kontolaimou, A. et al. (2016). A typology of European countries based on innovation efficiency and technology gaps: The role of early-stage entrepreneurship, Economic Modelling, 52, 477-484.

Kravtsova, V. \& Radosevic, S. (2012). Are systems of innovation in Eastern Europe efficient?, Economic Systems, 36, 109-126.

Laforet, S. (2010). A framework of organizational innovation and outcomes in SMEs, International Journal of Entrepreneurial Behaviour \& Research, 17(4), 380-408.

Li, X. (2009). China's regional innovation capacity in transition: An empirical approach, Research Policy, 38, 338-357.

Macdonald-Jankowski, D. \& Dozier, M. (2003). Systematic Review. Part 2. Conducting a Systematic Review, Asian J Oral Maxillofac Surg, 15, 231-237.

Mariz-Pérez, R. M. et al. (2012). The relevance of human capital as a driver for innovation, Cuadernos de Economía, 35, 68-76.

Matei, M. M. \& Aldea, A. (2012). Ranking National Innovation Systems according to their technical efficiency, Procedia - Social and Behavioral Sciences, 62, 968-974.

Patton, M. Q. (1990). Qualitative evaluation and research methods. London: Sage.

Păunescu, C. \& Argatu, R. (2020). Critical functions in ensuring effective business continuity management. Evidence from Romanian companies, Journal of Business Economics and Management, 21(2), 497-520.

Păunescu, C. \& Molnar, E. (2020). Country’s Entrepreneurial Environment Predictors for Starting a New Venture-Evidence for Romania, Sustainability, 12, 1-18. 
Păunescu, C. et al. (2018). Business impact analysis for business continuity: Evidence from Romanian enterprises on critical functions, Management \& Marketing. Challenges for the Knowledge Society, 13(3), 1035-1050.

Popescu, N. E. (2014). Entrepreneurship and SMEs Innovation in Romania, Procedia Economics and Finance, 16, 512-520.

Roman, M. (2010). Regional efficiency of knowledge economy in the new EU countries: The Romanian and Bulgarian case, February 2010, Retrieved from https://mpra.ub.unimuenchen.de/23083/.

Sandu, S. et al. (2015). The R\&D and innovation systems in Romania and Bulgaria in the EU context, Procedia Economics and Finance, 32, 1804-1826.

Saunders et al. (2012). Research Methods for Business Students. Sixth edition, Harlow, Pearson.

Szabo, K. Z., \& Herman, E. (2012). Innovative Entrepreneurship for Economic Development in EU, Procedia Economics and Finance, 3, 268-275.

Szeto, E. (2000). Innovation capacity: working towards a mechanism for improving innovation within an inter-organizational network, The TQM Magazine, 12(2), 149-158.

Talmaciu, M. (2012). Considerations regarding the development of Romanian regional economies through innovation and entrepreneurship, Procedia Economics and Finance, 3, 914-920.

Tilebein, M. (2006). A complex adaptive systems approach to efficiency and innovation, Kybernetes, 35 (7), 1087-1099.

Wang, S. et al. (2016). Regional innovation environment and innovation efficiency: the Chinese case, Technology Analysis \& Strategic Management, 28(4), 396-410.

Wonglimpiyarat, J. (2010). Innovation index and the innovative capacity of nations, Futures, 42, 247-253.

Zaman, G. \& Blănaru, A. (2008). Romania in EU context. Competitiveness and knowledge-based economy, Annales Universitatis Apulensis Series Oeconomica, 10, 1-21.

Zygiaris, S. (2009). Regional Innovation System Failures and Highlights, The Journal of the Romanian Regional Science Association, 3(2), 1-23. 